\title{
Commentary: Extracorporeal membrane oxygenation transport-The road less traveled (until now)
}

\author{
Jonathan D'Cunha, MD, PhD
}

\footnotetext{
From the Division of Lung Transplantation and Lung Failure, Department of Cardiothoracic Surgery, University of Pittsburgh Medical Center, Pittsburgh, Pa.

Disclosures: Author has nothing to disclose with regard to commercial support.

Received for publication Jan 1, 2019; accepted for publication Jan 1, 2019; available ahead of print Jan 31, 2019.

Address for reprints: Jonathan D'Cunha, MD, PhD, Department of Cardiothoracic Surgery, University of Pittsburgh Medical Center, UPMC Presbyterian, 200 Lothrop St, Suite C-900, Pittsburgh, PA 15213 (E-mail: dcunhaj@upmc.edu).

J Thorac Cardiovasc Surg 2019;157:1709-10

$0022-5223 / \$ 36.00$

Copyright (c) 2019 by The American Association for Thoracic Surgery

https://doi.org/10.1016/j.jtcvs.2019.01.002
}

The use of extracorporeal membrane oxygenation (ECMO) has seen a rapid rise in its implementation for those patients with cardiac and respiratory failure. ${ }^{1}$ Beginning in the 1970s, ECMO transport has gained increasing attention, to the point that many institutions provide resources for this less-traveled road. ${ }^{2}$ In fact, guidelines for transport have been put forth and are available from the Extracorporeal Life Support Organization's webpage (http://www. elso.org). More recently, studies from the Conventional Ventilatory Support vs Extracorporeal Membrane Oxygenation for Severe Adult Respiratory Failure (CESAR) trial and the consensus statement from ECMONet concluded that interhospital transports to high-volume ECMO centers save lives. ${ }^{3,4}$ Many centers have no further recourse for the patient in unstable condition, and the use of ECMO can facilitate a safe transfer when medical care has been maximized. There is no doubt that the trends we are seeing have driven high-volume tertiary referral centers, and there may be a point where a true hub-and-spoke model for referrals to a high-volume center is formalized.

In this issue of the Journal, Tipograf and colleagues ${ }^{5}$ present their experience at a single high-volume institution with 265 adult patients who were transported to their center of excellence. This is an important contribution, because essentially this group has established the safety profile for ECMO transfer. It is a logical follow-up from their original publication in in 2015, which evaluated 100 patients who were successfully transported. ${ }^{6}$ In their work in this issue, Tipograf and colleagues, ${ }^{5}$ who have expanded their clinician involvement by and other aspects of the program on the basis of their experience, report a more mature set of findings in 165 additional patients. They carefully selected the patients, with only $16 \%$ of ECMO referrals accepted, and they sent a standardized team of 2 critical care paramedics, a cardiothoracic surgeon, a surgical ECMO fellow, and a perfusionist. They compared their two eras (the first 100 transfers being in era $\mathrm{A}$ and the next 165 transfers being

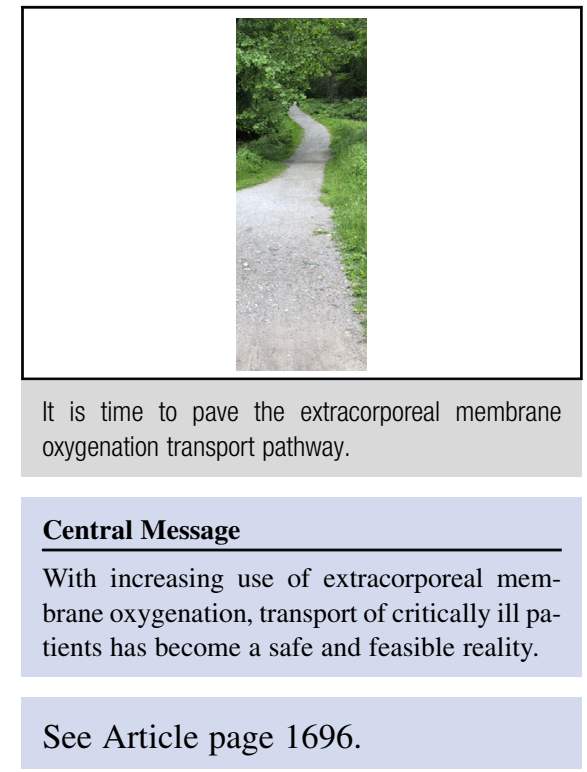

in era B). For the median distance of 16.9 miles traveled, they used ambulances as the primary mode of transportation. Impressively, through 265 transports, there was no transport-related morbidity or mortality. There have been several recent studies that support their findings that patients cannulated and transported by mobile ECMO teams have comparable outcomes. ${ }^{7,8}$

The work reported in this issue was the highest reported cohort with ECMO transports until an impressive series from the Karolinska Institute emerged recently. ${ }^{9}$ In that work, Fletcher-Sandersjöö and colleagues ${ }^{9}$ presented their experience through 21 years with 900 interhospital ECMO transports. There were 474 adults in the series. Complications were noted in $26 \%$ of the adults. These complications appeared to be associated mostly with venoarterial ECMO and transport by fixed-wing aircraft. Severe complications did not affect intensive care unit mortality, implying that these highly trained teams and centers were able to manage these complications successfully. There were only 1 adult death and 2 deaths overall in the Karolinska series. Fletcher-Sandersjöö and colleagues ${ }^{9}$ provided important data demonstrating that interhospital ECMO transportation is safe and feasible when conducted by an experienced center.

Both these timely studies provide much needed evidence and support for the safety and feasibility of ECMO transport. As our experience with ECMO has grown, the next 
logical step is for that experience to broaden to the safe transport of patients from centers with limited resources to high-volume centers, where the outcomes in these studies may be supported and improved upon. The lessons learned will provide the basis for implementation of established protocols in a broader setting as part of multicenter trials. It is strongly believed that this lifesaving, high-acuity, and costly technology has a role, and consensus guidelines for its cost-effective use should be the focus of a major initiative for optimal resource allocation. The time has come to pave this historically less-traveled road.

\section{References}

1. Raman L, Dalton HJ. Year in review 2015: extracorporeal membrane oxygenation. Respir Care. 2016;61:986-91.

2. Niziolek KC, Preston TJ, Osborn EC. Transport while on extracorporeal membrane oxygenation support. Crit Care Clin. 2017;33:883-96.

3. Combes A, Brodie D, Bartlett R, Brochard L, Brower R, Conrad S, et al; International ECMO Network (ECMONet). Position paper for the organization of extracorporeal membrane oxygenation programs for acute respiratory failure in adult patients. Am J Respir Crit Care Med. 2014;190:488-96.

4. Peek GJ, Mugford M, Tiruvoipati R, Wilson A, Allen E, Thalanany MM, et al. CESAR trial collaboration. Efficacy and economic assessment of conventional ventilatory support versus extracorporeal membrane oxygenation for severe adult respiratory failure (CESAR): a multicentre randomised controlled trial. Lancet. 2009;374:1351-63.

5. Tipograf Y, Liou P, Oommen R, Agerstrand C, Abrams D, Brodie D, et al. A decade of interfacility extracorporeal membrane oxygenation transport. $J$ Thorac Cardiovasc Surg. 2019;157:1696-706.

6. Biscotti M, Agerstrand C, Abrams D, Ginsburg M, Sonett J, Mongero L, et al. One hundred transports on extracorporeal support to an extracorporeal membrane oxygenation center. Ann Thorac Surg. 2015;100:34-9; discussion 39-40.

7. Bréchot N, Mastroianni C, Schmidt M, Santi F, Lebreton G, Hoareau AM, et al. Retrieval of severe acute respiratory failure patients on extracorporeal membrane oxygenation: any impact on their outcomes? J Thorac Cardiovasc Surg. 2018;155: 1621-9.e2.

8. Broman LM, Holzgraefe B, Palmér K, Frenckner B. The Stockholm experience: interhospital transports on extracorporeal membrane oxygenation. Crit Care. 2015;19:278.

9. Fletcher-Sandersjöö A, Frenckner B, Broman M. A single-center experience of 900 interhospital transports on extracorporeal membrane oxygenation. Ann Thorac Surg. 2019;107:119-27. 